\title{
The Role of Neuropeptide Endopeptidases in Cutaneous Immunity
}

T.E. Scholzen

\section{Contents}

$8.1 \quad$ Introduction $\ldots \ldots \ldots \ldots \ldots \ldots \ldots \ldots \ldots \ldots$

8.2 Intracellular Endoproteases Convert Inactive Prohormones to Bioactive Mediators . . . . . . 76

8.2.1 Cellular Localization and Expression ........ . 76

8.2.2 Molecular Biology and Structural Properties ... 76

8.2.3 Physiologic Significance . . . . . . . . . . . 77

8.3 Dipeptidylpeptidase IV/CD26 .......... 77

8.3.1 Cellular Localization and Expression . . . . . . . . 77

8.3.2 Molecular Biology and Structural Properties ... 77

8.3.3 Functional Roles of DPIV/CD26 in Immunity and Inflammation. . . . . . . . . . . . . . . 77

8.3.4 DPIV/CD26 and the Development of Neoplasms . . . . . . . . . . . . . . . . . . . .

8.4 Ectopic Zinc Metalloendopeptidases:

Neprilysin and Angiotensin-Converting

Enzyme ......................

8.4.1 Cellular Localization and Expression . . . . . . . . .

8.4.2 Molecular Biology and Structural Properties ...

8.4.3 Physiologic Roles of NEP and ACE ... . . . . . .

8.4.4 Zinc Metalloproteases Terminate

"Danger Signals" . . . . . . . . . . . . . . .

8.4.5 Regulated NEP and ACE: A Protective Role

Against Ultraviolet Irradiation? . . . . . . . . . . .

8.4.6 Role of NEP and ACE in Cutaneous Wound

Healing and Plasticity ..............

8.4.7 Development of Neoplasms: Shutting Off

Growth-Promoting Signals is the Key . . . . . . . .

8.4.8 NEP and ACE: Are There Functional Roles

in Psoriasis, Alopecia Areata, and Acne?. . . . . . .

Summary for the Clinician $\ldots \ldots \ldots \ldots \ldots .84$

References.....................

Synonyms Box: Neprilysin, neutral endopeptidases, common acute lymphoblast leukemia antigen (CALLA) CD10, enkephalinase, CD10, NEP, EC 3.4.24.11;

\section{Key Features}

> Proteolytic processing and degradation plays an important role in modulating the generation and bioactivity of neuroendocrine peptide mediators, a class of key molecules in cutaneous biology.

> Accordingly, the cellular localization and expression, and the molecular biology and structural properties of selected intracellular prohormone convertases and ectopically expressed zinc-binding metalloendoproteases are discussed.

> A special reference will be made to the physiologic and pathophysiologic significance of these endopeptidases in cutaneous immunobiology.

> Because of the number of pathologically relevant changes in inflammation and tumor progression that can be directly attributed to neprilysin and angiotensin-converting enzyme, a particular focus will be on the role of these enzymes in modulating innate and adaptive immune responses in the skin.

angiotensin-converting enzyme, dipeptidyl carboxypeptidase, kininase II, ACE, CD143, EC 3.4.15.1; Dipeptidyl peptidase IV, CD26, EC 3.4.14.5

Abbreviations: $A C E$ Angiotensin-converting enzyme, $A C T H$ Adrenocorticotropin, Ag Antigen, Ang Angiotensin, $B K$ Bradykinin, CGRP Calcitonin gene-related peptide, CTCL Cutaneous T-cell lymphomas, $D C$ Dendritic cell(s), DPIV Dipeptidyl peptidase IV, EAE Experimental autoimmune encephalomyelitis, ECE Endothelin-converting enzyme, EC Endothelial cells, END Endorphin, $M C_{x}$ Melanocortin receptor, $M H C$ 
Major histocompatibility complex, $M S H$ Melanocytestimulating hormone, NEP Neprilysin, PACAP Pituitary adenylate-cyclase-activating polypeptide, $P C$ Prohormone convertase, $P O M C$ Proopiomelanocortin, $S P$ Substance P, TC T-cell(s), $T_{H}$ helper T-cells, $T_{\text {eff }}$ Effector T-cells, VIP Vasoactive intestinal peptide

\subsection{Introduction}

Almost every aspect of cutaneous cellular and tissue function, including proliferation, differentiation, maturation, communication, antigen (Ag) presentation, and survival of cells as well as hair growths, eccrine gland function, wound healing, and tissue regeneration, is modulated by neuropeptides. It is thus quite comprehensible that a variety of mechanisms have evolved, which limit their temporal, spatial, and developmental bioactivity. These include temporally and spatially controlled mediator generation and release, the regulated expression of specific receptors on cellular targets, receptor desensitization and resensitization, and the clearance of excessive extracellular peptides. Proteases participate in several of the above mechanisms; thus taking a key regulatory role in cutaneous peptide mediator bioavailability. As such they serve to generate bioactive peptides from inactive prohormones in order to initialize inflammatory and trophic responses. Importantly, they also rapidly terminate the bioactivity of neuropeptides released from nerve terminals or endocrine cells and thus prevent the development of a neuropeptides-initialized or -augmented deleterious chronic inflammation. In addition, microbial invaders or parasites use peptidases as an evolutionarily successful strategy to manipulate the host immune defenses. Peptidases play an important role in cutaneous plasticity and wound healing by modulating trophic neuropeptide activities. Moreover, beyond a mere catalytic function, ectopeptidases trigger specific intracellular signal transduction, participate in cell-cell or cell-virus recognition, and mediate or modulate binding to extracellular matrix components. This chapter highlights some of the current knowledge on peptidase function in cutaneous immunity and outlines clinical and potential future research areas derived from key functions of these enzymes. In addition, as zinc metalloproteases are among the largest group of proteases relevant for the extracellular cleavage of neuroendocrine mediators, a special emphasis will be made on this class of proteases.

\subsection{Intracellular Endoproteases Convert Inactive Prohormones to Bioactive Mediators}

\subsubsection{Cellular Localization and Expression}

Despite the important role that intracellular endoproteolytic processing and activation of prohormones, particularly of proopiomelanocortin (POMC), by prohormone convertase (PC) plays for cutaneous physiologic and pathophysiologic responses, this chapter's focus centers on functions of extracellular proteases. Importantly, with respect to cutaneous melanocortin generation, some extracellular proteases may also be capable of processing larger precursors, resulting in bioactive melanocortin receptor-(MC-) activating POMC peptides. Neuroendocrine hormones such as adrenocorticotrophin (ACTH) or $\alpha$-melanocyte-stimulating hormone $(\alpha-\mathrm{MSH})$ are released in the skin as part of an intrinsic cutaneous hypothalamus-pituitary-adrenal axis and mediate the cutaneous response to invasive and noninvasive exogenous stress via MC receptors [11,87]. PC are an evolutionary conserved class of secretory serine proteases of the subtilisin/kexin-type that comprise PC1/3, PC2, furin/PACE, PACE4, PC4, PC5/6, PC7, and SKI-1 [81]. POMC peptides and POMC processing enzymes including PC1, PC2, PACE4, or furin have been identified in a variety of skin cells, skin appendages, cutaneous carcinoma cells, and immune cells (reviewed in $[10,42,81]$ ).

\subsubsection{Molecular Biology and Structural Properties}

The conserved structure of the PC catalytic domain suggests that these proteases have evolved from a common ancestral precursor gene. Subtilisin/kex family PC are specialized for cleaving multiple hormones, growth factors, and receptor precursors by limited internal proteolysis at single or multiple basic recognition sites, within the general motive K/R$(\mathrm{X})_{\mathrm{n}}-\mathrm{K} / \mathrm{R} \downarrow$ [81]. PC expression and activity is strictly regulated at the tissue, cell, or subcellular level. 
Autocatalytic activation of PC zymogens is another means to control PC bioactivity within the secretory pathway. In some cases, that is, for PC2, cofactors such as the binding protein $7 \mathrm{~B} 2$ are required for efficient zymogen activation of proPC and full functional activity $[50,81]$.

\subsubsection{Physiologic Significance}

The primary function of cutaneous $\mathrm{PC}$ is the conversion of the POMC prohormone in various skin cells. The resulting generation of $\alpha-\mathrm{MSH}, \mathrm{ACTH}$, or $\beta$ endorphin is highly relevant for skin immunity, stress response, and pigmentation (for more details see Chap. 6 and [42]). Studies of PC1/3- and PC2-deficient mice revealed that deletion of these enzymes impairs the processing of POMC and other prohormones, although some redundancies might exist [71]. The pathophysiologic consequences of a dysregulated PC expression for cutaneous immunity have not yet been fully explored. The simultaneous episodic expression of PC1, PC2, and POMC during the murine hair cycle suggests a regulatory function of $\mathrm{PC}$ for the pilosebaceous unit [49]. POMC, MC, and PC expression in some skin cells are synergistically regulated by UV light, melanocortins, and pro-inflammatory cytokines in vitro. These stimuli may simultaneously increase production and responsiveness of cutaneous cells to POMC peptides, although this has not been conclusively confirmed in vivo $[73,76]$. An upregulated $\mathrm{PC} 1, \mathrm{PC} 2$, and furin expression positively correlates with malignant neuroendocrine tumors and of several other cancers [39], suggesting that subtilisin/kex-like convertases may increase tumorigenesis and aggressiveness by augmenting processing and activation of mitogenic peptides. Thus, PC both serve as a prognostic marker for tumor progression and constitute an important pharmacologic target in cancer therapy, since PC inhibition drastically reduced the metastatic properties of certain tumor cells $[39,71]$. Interestingly, some bacterial toxin precursors (e.g., Diphteria toxin, Botulinum neurotoxin), as well as viral glycoproteins of HIV-1, Ebola, and others viruses need proteolytic PC activation for their toxic or infectious capacity and/or the cell-cell spreading. This demonstrates the high relevance of PC for the cutaneous response to infectious agents and, therefore, PC inhibition could be beneficial for abrogating microbial-induced cytopathicity (reviewed in [39]).

\subsection{Dipeptidylpeptidase IV/CD26}

\subsubsection{Cellular Localization and Expression}

Dipeptidyl peptidase (DP) IV (CD26, EC 3.4.14.5) is a multifunctional homodimeric glycoprotein with functional roles in hematology, endocrinology, immunology, endothelial cell (EC), and cancer biology and metabolism. DPIV is part of a six member gene family of enzymes that, in addition to DPIV, includes fibroblast activating protein (FAP), DP-like (DPL) 1, DPL2, DP8, DP9, and prolyloligopeptidase (POP) [13,27]. Human DPIV is ubiquitously expressed by capillary EC, activated lymphocytes, DC subpopulations, and on apical surfaces of epithelial cells [27]. In addition, soluble forms of the enzyme have been described. Cutaneous DPIV is expressed on keratinocytes [60], fibroblasts [59], melanocytes [55], the axon-Schwann cell interface [20], and TCs [41].

\subsubsection{Molecular Biology and Structural Properties}

The structural and biochemical properties of DPIV have been described in detail in [27]. The DPIV gene product is a 766 amino acid (AA) ectoprotease with an apparent monomeric molecular weight of about $110 \mathrm{kDa}$. Characteristically, full functional DPIV peptidase activity requires homodimerization between one of two extracellular hydrolase domains. This results in a rather unique post-proline dipeptidyl aminopeptidase activity of DPIV by cutting off N-terminal X-P or X-A dipeptides from polypeptides. A variety of DPIV peptide substrates have functional relevance for skin (patho) physiology. These comprise at least $9 \mathrm{CCL}$ and $\mathrm{CXC}$ chemokines (i.e., CCL5, RANTES, or CXCL10, IFN $\gamma$-induced protein), hormones (i.e., glucagon-like peptides (GLP), prolactin, leutinizing hormone $\alpha$, chorionic gonadotropin $\alpha$ chain), enkephalins, and neuropeptides such as neuropeptide Y, pituitary-adenylate cyclase-activating polypeptide (PACAP) 38, vasoactive intestinal peptide (VIP), and SP.

\subsubsection{Functional Roles of DPIV/CD26 in Immunity and Inflammation}

There is compelling evidence that DPIV has a number of important physiologic functions in endocrinology and metabolism. For instance, DPIV degrades GLP and glucose-dependent insulinotropic peptide. The 
inhibition of DPIV results in accumulation of these peptides, which stimulates greater insulin production and is therefore beneficial for the treatment of insulinindependent Diabetes mellitus (see [27] for details). DPIV/CD26 has gained considerable interest as a $\mathrm{T}$ cell (TC) activation marker, and is also expressed by some dendritic cell (DC) subpopulations [24]. Accordingly, DPIV expression, together with other TC activation markers such as CD25, CD71 CD45RO, or CD29, increases significantly after antigenic and mitogenic stimulation, or treatment with the $\mathrm{T}$ helper $\left(\mathrm{T}_{\mathrm{H}}\right) 1$ cytokine IL-12. Overexpression of human CD26 in TC of transgenic mice reduces thymus cellularity, impairs thymocyte proliferation, and increases the number of peripheral apoptotic $\mathrm{CD}^{+}$- or $\mathrm{CD}^{+}-\mathrm{TC}$, indicating the importance of CD26 for peripheral T lymphocyte homeostasis [85]. Interestingly, DPIV upregulation increases degradation of VIP and PACAP, two neuropeptides known to trigger $\mathrm{T}_{\mathrm{H}} 2$ immune responses via IL-4, IL-5, and IL-10 induction in CD4 ${ }^{+}$TC [25,27]. Up- or downregulated CD26 expression may therefore shift the $T_{H} 1 / T_{H} 2$ balance $[72,82]$ with high relevance for psoriasis, atopic dermatitis [5], or rheumatoid arthritis (RA) [8]. However, studies of murine experimental autoimmune encephalomyelitis (EAE) and RA revealed surprising discrepancies between functional inhibition of DPIV by genetic knock-out and pharmacologic inhibitors. While DPIV-inhibiting drugs delayed the onset and severity of experimental EAE or RA, missing CD26 activity in knock-out mice or in human patients was inversely correlated to the severity of Ag-induced RA or EAE. Thus, DPIV inhibitors may have additional functional targets [8]. CD26 expressed in lipid rafts within the immunologic synapse also transduces intracellular signals that overlap with the TC receptor/CD3 signaling pathways. DPIV enzyme activity may therefore be dispensable for full immunologic activity of TC, since costimulatory activity of CD26 in vitro is retained in DPIV mutants that lack hydrolase activity [27].

\subsubsection{DPIV/CD26 and the Development of Neoplasms}

The skin is the host for a number of extranodal nonHodgkin cutaneous TC lymphomas (CTCL) [41]. Strikingly, in the most relevant types of CTCL, mycosis fungoides (MF) and Sézary syndrome (SS), skin-homing malignant $\mathrm{CD}^{+} \mathrm{CD}^{+} \mathrm{CD}^{\text {variable }} \mathrm{CLA}^{+} \mathrm{CCR}^{+} \mathrm{TCs}$ characteristically lack CD26 expression. DPIV/CD26 is an important diagnostic marker for SS or MF, and also highly relevant for the pathophysiology of CTCL [88]. Missing CD26 compromises the TC capability to degrade the constitutively expressed cutaneous stem cell factor 1, which may promote homing of malignant TC into the skin [58]. Infiltrating CTCL-CD26TC then generate an immunosuppressive $\mathrm{T}_{\mathrm{H}} 2$ environment with immature DC incapable of efficiently presenting phagocytozed material derived from apoptotic malignant $\mathrm{TC}$. The resulting regulatory $\mathrm{TC}\left(\mathrm{T}_{\text {reg }}\right)$ then contribute to immunosuppression and CTCL-TC tolerance [41]. Evidently, DPIV may also be relevant for growth, invasiveness, and metastasis of other tumors. For instance, DPIV expression is inversely correlated to progression of melanoma and even absent in metastatic melanoma [67,101]. Conversely, overexpression of DPIV in melanoma cells suppresses tumor progression in nude mice possibly independently of a DPIV enzymatic activity. Likewise, DPIV interacts with ECM components such as collagen, fibronectin, E-cadherin, or tissue inhibitors of matrix metalloproteases [103]. Consequently, a higher DPIV expression enhances adherence of tumor cells to the ECM, which may be anti-invasive by preventing detachment of tumor cells from the solid tumor. Alternatively, DPIV may also hamper basic fibroblast growth factor (bFGF) mitogenic signaling pathways [106]. In summary, DPIV/CD26 (patho-)physiologic effects in tumorigenesis possibly depend on a direct interaction with ECM components or an indirect degradation of important inflammatory mediators.

\subsection{Ectopic Zinc Metalloendopeptidases: Neprilysin and Angiotensin-Converting Enzyme}

\subsubsection{Cellular Localization and Expression}

Neprilysin (NEP, EC 3.4.24.11, CD10) and angiotensinconverting enzyme ACE (EC 3.4.15.1, CD143), two mechanistically related EC surface zinc metallopeptidases, are widely distributed in the body and highly expressed in the vascular endothelium, kidney epithelium, lung, or CNS $[99,100]$. NEP ("enkephalinase" or "common acute lymphoblastic leukemia antigen" (CALLA) ) was initially isolated more than 30 years ago as an insulin B chain-degrading enzyme abundantly expressed in the renal brush border membrane [100]. The history of the ACE family has accomplished a journey from the original discovery and isolation of ACE 50 years ago as "hypertension-converting 
enzyme" until the recent identification of the related carboxypeptidase ACE2 as vasopeptidase and coreceptor for the severe acute respiratory syndrome corona virus (SARS-CoV) [30,31]. The somatic isoform of ACE and ACE2 are abundantly expressed in the vascular endothelium surface of the lung and in brush-border membranes of kidney, intestine, placenta, and the choroid plexus. A soluble isoform of somatic ACE is present in the plasma, and a smaller isoenzyme essential for male fertility is expressed in the testis $[30,99]$. Cutaneous NEP as well as components of the reninangiotensin system (RAS) including ACE and ACE2 are expressed in basal keratinocytes, hair follicles, eccrine and sebaceous glands, the microvascular endothelium, and large nerves or nerve-ensheathing Schwann cells (reviewed in $[31,75,89]$ ). NEP and ACE, but not ACE2, are expressed in DC, macrophages, or TC and in bone marrow stromal cells, suggesting functional roles in hematopoiesis and immunity $[15,31,38,45,47]$. A recently identified secreted homologue NEP2 related to D. melanogaster NEP is expressed in the renal tube and in testis, but its relevance for skin immunity still has to be determined [96].

\subsubsection{Molecular Biology and Structural Properties}

Despite structural similarities between ACE and NEP, NEP is evolutionarily closer related to the bacterial Zn protease thermolysin. NEP homologues were identified in all organisms from simple prokaryotes to higher vertebrates, including men [100]. The mammalian NEP family now comprises at least seven members, with NEP and endothelin-converting enzyme (ECE, EC 3.4.24.71) as best characterized. The molecular biology of NEP is described in [69]. As a type II integral membrane protein ectopeptidase, NEP $(90-110 \mathrm{kDa})$ consists of a short N-terminal intracellular domain, a transmembrane anchor, and a large C-terminal extracellular domain that contains a $\mathrm{Zn}$ coordinating active site constituted by a HExxH and an ExxA/GD sequence [100]. Two closely related ACE isoenzymes (somatic and germinal) have been identified in mammalian cells. Somatic ACE (150-180 kDa) is a type I C-terminally membrane-anchored glycoprotein that contains two highly homologous extracellular domains (N-domain, C-domain), each bearing a zinccoordinating catalytic site. By contrast, the smaller testicular ACE involved in male fertility contains a single catalytic site identical to the C-terminal domain of somatic ACE [44,99].

\subsubsection{Physiologic Roles of NEP and ACE}

Much help in understanding NEP and ACE function is derived from using mercaptoalkanoyl inhibitors such as captopril [99], or selective NEP inhibitors such as thiorphan and phosphoramidon [69]. The latter is a streptomyces tanashiensis product suggesting an evolutionary old relationship between zinc metalloproteases-expressing prokaryotes and eukaryotes [100]. In addition to its widespread role in turning off neuronal signals transmitted via SP or enkephalins, the panel of today's known NEP substrates includes, but is not limited to, vasoactive peptides such as bradykinin (BK) or angiotensin (Ang) I, atrial natriuretic peptide (ANP), growth factors such as bombesin, chemotactic peptides such as fMLP, and most recently $\beta$-amyloid (A $\beta$ ) peptide, the key initiator of Alzheimer's disease (AD) $[35,86,100]$. The structure of the mammalian NEP extracellular domain limits accessibility of the catalytic site for substrates. Therefore, and in contrast to the protease activity of thermolysin, NEP is an oligopeptidase cleaving peptides predominantly non-terminal before hydrophobic AA residues [69]. ACE's active sites display endopeptidase and dipeptidyl carboxypeptidase activity, which differ in their $\mathrm{pH} / \mathrm{chlo-}$ ride dependency and substrate specificity $[36,105]$. A prominent physiological feature of NEP and ACE is their overlap in competitively cleaved substrates, resulting in opposing roles in renal and cardiovascular regulation (reviewed in $[9,86]$ ). The successful 30 year use of ACE inhibitors to therapeutically intervene with hypertension and cardiovascular dysfunction has encouraged attempts to additionally inhibit related enzymes such as NEP and recently ECE with a single drug. Advantage of such dual ACE/NEP- or triple ACE/NEP/ECE-specific "vasopeptidase inhibitors" is a limited generation of proinflammatory, blood pressure-rising vasoconstrictors (Ang II, ET-1), the accumulation of vasodilators (BK, Ang $_{1-7}$ ), and additionally of the diuretic ANP. Consequently, vasopeptidase inhibition lowers blood pressure, diminishes cardiac hypertrophy and fibrosis, promotes renal natriuresis and diuresis, but also bears the risk of serious adverse effects $[3,9,91]$.

\subsubsection{Zinc Metalloproteases Terminate "Danger Signals"}

NEP and ACE are ancient components of the innate and adaptive immune response of higher vertebrates. First, they participate in the immediate host defense - unfortunately with initial advances for a microbial intruder. Bacterial thermolysin-like peptidases facilitate 
entry into the host by degrading peptides with antimicrobial properties, for instance nerve-derived host SP, but also $\alpha$-MSH or adrenomedullin [93] [Fig. 8.1(1)]. In parallel, peptidases enhance the bacterial invasiveness by degrading ECM (collagen IV) and facilitate the entry into the host's circulation [Fig. 8.1(2,3)] [51,52]. The complex peptidase-substrate interplay is reflected by the fact that - from the defendant's point of view - limited degradation of vasoactive and neuropeptides may be advantageous in early inflammation. Neuronal and cellular-derived SP, CGRP, or BK induce a vicious cycle of releasing IL-1 or TNF $\alpha$ from cutaneous cells that conversely promote the release and axonal transport of SP and CGRP in sensory neurons ([65,68,74,75], and included references.). Indeed, a downregulated NEP expression by irritants or endotoxins as observed in respiratory tract or intestinal inflammation suggests that prolonged activity of SP and BK may be advantageous for kick-off and progression of (neurogenic) inflammation and subsequent events, such as a full Ag-specific inflammatory response at the site of $\mathrm{Ag}$ challenge.

Numerous studies using vasopeptidase inhibitors or NEP-/ACE-deficient mice confirm the significance of NEP and ACE for cutaneous innate immunity $[65,68,74,75]$. The lack of NEP increased inflammatory responses and lethality in various murine inflammatory models (reviewed in [75]), and functional deletion of NEP and/or ACE markedly exacerbated murine allergic contact dermatitis (ACD) $[23,77,78]$. Missing NEP or ACE particularly on, or in the vicinity of, hematopoietic and immune cells modulates hematopoiesis [38], profoundly disturbs the local immune cell-activating cytoand chemokine microenvironment, and imbalances pro- and anti-inflammatory neuropeptides. The latter fine-tune the DC:TC interface and $\mathrm{T}_{\mathrm{H}}$ differentiation in adaptive immunity. Initialization of cutaneous delayedtype hypersensitivity requires activation and migration

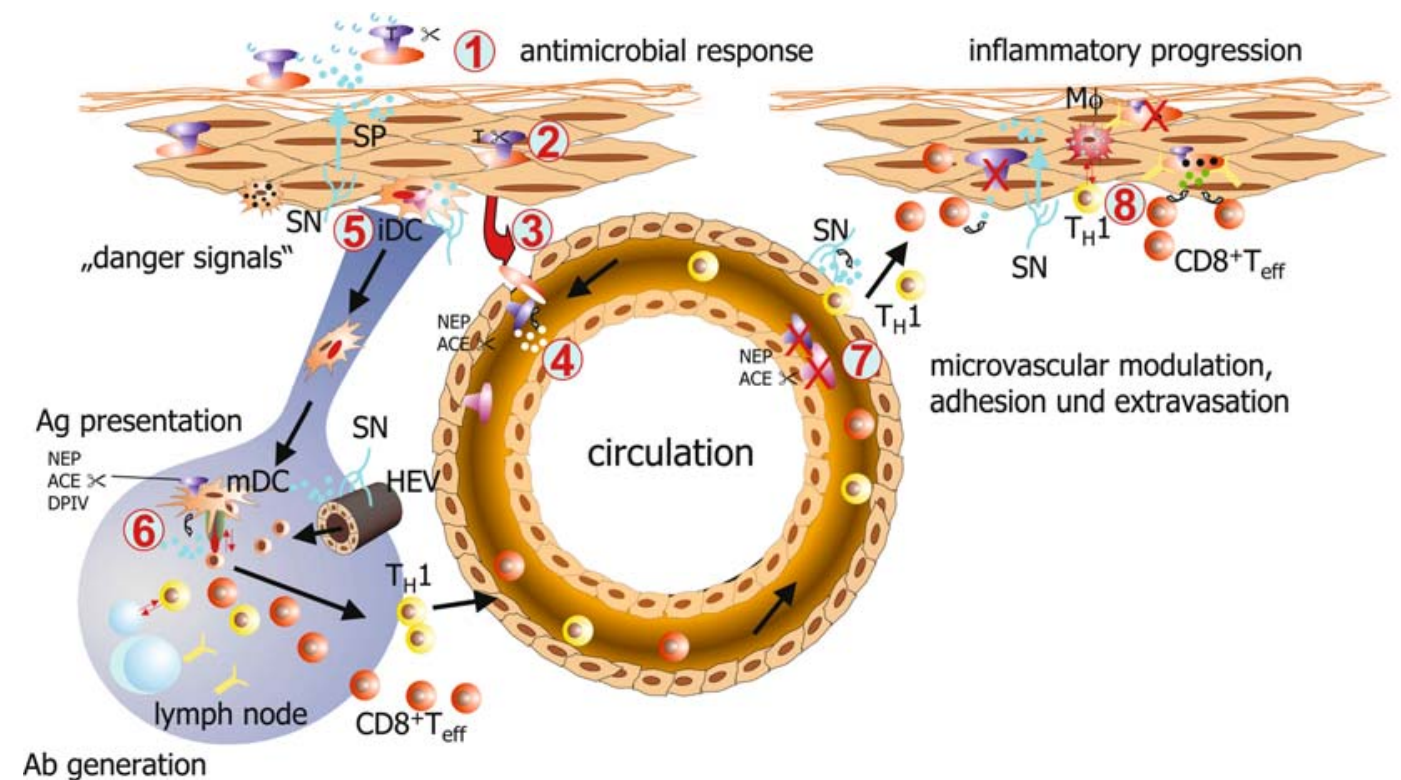

Fig. 8.1 Endopeptidases control multiple steps in inflammation and initialization of adaptive immunity. Intruding bacterial pathogens utilize thermolysin-like peptidases $(\mathrm{T})$ to partly degrade antimicrobial neuropeptides, for example, substance $P$ (SP) derived from sensory neurons (SN) or keratinocytes (1). By degrading extracellular matrix, peptidases facilitate microbial entry into the host (2) and accession to the vascular lumen (3). In some cases, host peptidases (NEP) may liberate anti-inflammatory peptides $(\alpha-\mathrm{MSH})$ from pathogen precursor molecules to compromise host's immunity (4). Released SP and other pro-inflammatory peptides serve as "danger signals" to activate residing immature dendritic cells (iDC) and induce DC maturation and migration into draining lymph node $(\mathrm{LN})(\mathbf{5})$. In the
LN, neuropeptides (SP) released from sensory nerves contacting high endothelial venules (HEV) or from matured DC (mDC) interacting with naïve T-cells (TC) promote T-helper $\left(\mathrm{T}_{\mathrm{H}}\right) 1$ polarization and clonal expansion of $\mathrm{T}_{\mathrm{H}} 1$ and $\mathrm{CD} 8+$ effector TC $\left(\mathrm{CD}^{+} \mathrm{T}_{\text {eff }}\right)$, particularly in the absence of NEP or ACE (6). Inflammation-downregulated peptidases at the site of ongoing inflammation promote vascular responses to released neuropeptides, as well as the recruitment and extravasation of inflammatory cells (7). In environment lacking functional NEP, prolonged activity of pro-inflammatory neuropeptides released from SN, macrophages $(\mathrm{M} \phi)$, or TC promote multiple leukocyte effector functions, and in parallel, the temporarily increased availability of growth factors facilitates recovery of the damaged tissue (8) 
[Fig. 8.1(5)] of Ag-laden dermal DC or Langerhans cells and contact to naïve $\mathrm{CD}^{+} \mathrm{TC}$ in skin-draining lymph nodes [Fig. 8.1(6)]. Vasoactive peptides such as $\mathrm{SP}, \mathrm{BK}$, and Ang II via $\mathrm{NK}_{1}, \mathrm{~B}_{2}$, and $\mathrm{AT} 1 / \mathrm{AT} 2$ receptors, respectively, profoundly modulate myeloid DC precursor differentiation [38] and boost important DC and TC functions (Fig. 8.2) [45]. APC (DC or macrophages) and TC express $\mathrm{NK}_{1}$ and $\mathrm{B}_{2}$ as well as RAS components (ACE, AT1/AT2 receptors) and constitute extra-neuronal sources of SP $[2,17,45,46,56]$. Importantly, SP and $\mathrm{BK}$ activate DC NF- $\mathrm{KB}$, a central transcription factor involved in DC maturation marker (CD11c, MHC) and costimulatory molecule (CD40, B7 molecules) expression, and thus NEP/ACE-deficiency may promote functional maturation of $\mathrm{CD} 11 \mathrm{c}^{+} \mathrm{DC}[2,45]$. Vice versa, antagonist blocking of $\mathrm{B}_{2}$ or $\mathrm{NK}_{1}$ receptors impairs $\mathrm{Ag}$ sensitization in mice lacking functional ACE or NEP, which could be mimicked by adoptive transfer of $\mathrm{NK}_{1}$ receptor antagonist-treated, Ag-pulsed wild type bonemarrow DC generated in vitro [23,77-79]. Exogenous or endogenous SP contributes to mitogen- or Ag-induced TC proliferation and promotes a $\mathrm{T}_{\mathrm{H}} 1$ response characterized by reduced IL-4/IL-5 and increased IL-2/IFN $\gamma$ expression $[45,74,75,79]$. Hence, prolonged bioavailability

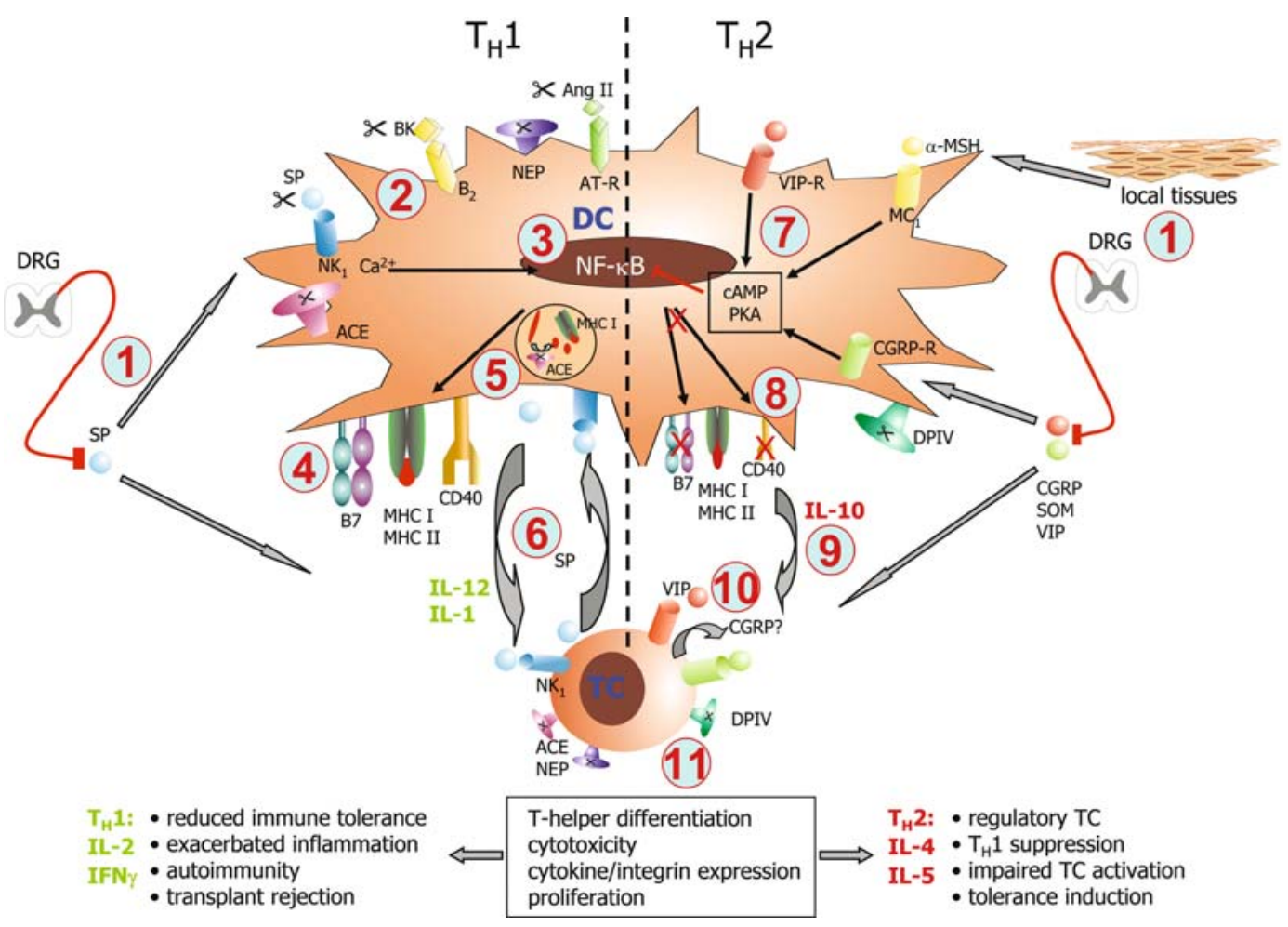

Fig. 8.2 Endopeptidases control the neuroendocrine hormonebalanced immune response transmitted by the immunologic synapse. Neuroendocrine and vasoactive peptides are released from cutaneous sensory neurons or cutaneous or lymphoid tissues (1). Ectopic (endo-) peptidase (NEP, ACE) mediator degradation controls the cellular accessibility of substance P (SP), bradykinin (BK), and angiotensin (Ang) II and activation of specific neurokinin $\left(\mathrm{NK}_{1}\right)$, bradykinin $\left(\mathrm{B}_{2}\right)$, and Ang $(\mathrm{AT})$ receptors expressed by dendritic cells (DC, (2)). SP, BK, and Ang II constitute endogenous danger signals that stimulate DC pro-inflammatory signal transduction pathways such as the release of $\mathrm{Ca}^{2+}$ and subsequent activation of NF- $\mathrm{\kappa B}(3)$. NF- $\mathrm{\kappa B}$ plays a central role in the induction of DC costimulatory B7 molecules, CD40 or major histocompatibility complex (MHC) expression, and pro-inflammatory T-helper $1\left(\mathrm{~T}_{\mathrm{H}} 1\right)$ cytokine release (4). Endopeptidases (e.g., ACE) improve the efficacy of antigen presentation to T-cells (TC) by intra- or extracellular trimming of peptides for MHC class I or II presentation (5). Endogenous SP from DC and TC may in an auto/ paracrine manner drive $\mathrm{T}_{\mathrm{H}} 1$ polarization under control of DC- or TC-expressed NEP and ACE (6). Via specific receptors expressed by $\mathrm{DC}$ and TC, $\alpha-\mathrm{MSH}$, calcitonin-gene related peptide (CGRP), somatostatin (SOM), and VIP trigger intracellular cAMP/protein kinase A (PKA) signal transduction (7). This inhibits endotoxin, cytokine-, or SP/BK-induced NF- $\mathrm{KB}$ activation and may promote a tolerogenic DC phenotype characterized by reduced TC costimulation (8), and release of anti-inflammatory cytokines (IL-10) (9). As demonstrated for VIP, such DC drive $\mathrm{T}_{\mathrm{H}} 2$ polarization, regulatory $\mathrm{TC}\left(\mathrm{T}_{\text {reg }}\right)$ development, and suppression of $\mathrm{T}_{\mathrm{H}} 1$ immune responses. $\mathrm{T}_{\mathrm{H}} 2$-inducing neuropeptides such as VIP (10) under the control of TC-expressed dipeptidyl peptidase IV/CD26 (DPIV, (11) ) may also directly trigger $\mathrm{T}_{\text {reg }}$ development from naïve $\mathrm{CD}^{+} \mathrm{CD} 25^{+} \mathrm{TC}$, which dampens $\mathrm{T}_{\mathrm{H}} 1$ and $\mathrm{CD}^{+} \mathrm{T}_{\text {eff }}$ responses 
of "proinflammatory" tachykinins and kinins constitutes an endogenous "danger signal" per se that generate fully matured MHC class II/I expressing DC, which drive a $T_{H} 1$ polarization and efficiently prime $T_{H}$ and effector cell $\left(\mathrm{T}_{\text {eff }}\right)$ responses (Fig. 8.2). This may be beneficial for fighting intracellular pathogens or malignant cells, but could also result in uncontrolled inflammation or even organ-specific autoimmunity. In contrast, " $\mathrm{T}_{\mathrm{H}} 2$ " neuropeptides such as VIP/PACAP, CGRP, or $\alpha$-MSH oppose the above by impairing Ag-presentation, and generating tolerogenic $\mathrm{DC}$ that attenuate $\mathrm{TC}$ activation. In addition, this may cause a $\mathrm{T}_{\mathrm{H}} 2$ differentiation and give rise to regulatory $\mathrm{CD} 4$ and IL-10-producing $\mathrm{CD} 8^{+}$ CD28-CTLA4 ${ }^{+}$TC that subsequently suppress Ag-specific $\mathrm{T}_{\mathrm{H}} 1$ mediated immune responses [25]. However, nature has predetermined additional roles for ACE and related peptidases for APC function in adaptive immunity. DC ACE is an important chaperone in the processing and MHC I-restricted presentation of viral and other peptides to $\mathrm{CD} 8^{+}$cytotoxic $\mathrm{T}$ lymphocytes (CTL) $[83,108]$. ACE interacts with the transporter associated with Ag presentation (TAP) complex that shuttles cytosolic peptides into the exocytic compartment for association with nascent MHC I molecules. Carboxyterminal ACE trimming of certain peptides improves their intracellular transport, and thus rescue their otherwise inefficient presentation to CTL [108]. Cathepsins, or a recently described asparaginyl endopeptidase, play a similar role in the endocytotic lysosomal pathway of DC and B-cells, with tremendous impact on MHC II-restricted Ag presentation [104]. Importantly, glycosylation or deamidation of certain self-proteins prevents cleavage by these proteases. Thus, a loss of these initially present post-translational modifications over time may suddenly render a self-protein susceptible for APC processing and recognition by TC, with fatal consequences for the maintenance of tolerance against self-antigens $[19,104]$. Thus, expression and specificity of endopeptidases in the MHC I or II compartment is essential for the control of peptide antigenicity.

\subsubsection{Regulated NEP and ACE: A Protective Role Against Ultraviolet Irradiation?}

Recent observations nurtured the hypothesis that NEP indirectly may have UV-protecting properties. UVB irradiation has been demonstrated to downregulate the NEP activity in human melanocytes. Pharmacologic NEP inhibition increased the efficacy of $\alpha-\mathrm{MSH}$ or $\mathrm{ACTH}$ to induce tyrosinase activity and microphtalia expression, suggesting that NEP plays a role in melanogenesis [1]. However, the role of UV in regulating NEP and ACE expression may depend on the cellular and functional context. UV light or cytokine-exposed microvascular EC displayed a time-dependent loss of cell surface ACE in vitro, whereas the initially low NEP expression increased [75]. This complex reciprocal regulatory system of vasopeptidases, which has also been observed in hypertensive rats [37], may be of particular significance for EC function. Recent bioanalytical studies demonstrated that endothelial NEP and ACE are highly relevant for processing stress $(\mathrm{ACTH})$ and anti-inflammatory hormone $(\alpha-\mathrm{MSH})$ [42]. However, instead of a mere removal of extracellular POMC peptides, NEP and ACE peptidolysis generated bioactive novel $\mathrm{MC}_{\mathrm{x}}$ agonists or antagonists distinct from the parental peptide. This phenomenon may have currently undefined functional roles for vascular biology and cutaneous inflammatory responses, since EC are an established source and target of POMC peptides. Of note, invertebrate parasites use vasopeptidases to generate anti-inflammatory immunosuppressive melanocortins from POMC precursors, suggesting an evolutionary conserved mechanism to compromise a host's immune system [42].

\subsubsection{Role of NEP and ACE in Cutaneous Wound Healing and Plasticity}

It is now widely appreciated that NEP expression downregulated by irritants, pro-inflammatory cytokines, endotoxins, or phorbol ester, respectively, increases the cellular accessibility of mediators and may promote inflammation and support cell growths as well as the development of neoplasms [34,95]. For instance, in nonhealing skin of diabetes mellitus patients or of mutant diabetic $d b / d b$ mice, NEP expression and activity are increased ([75] and included references.). SP and CGRP may contribute to wound healing, as they promote keratinocyte, endothelial cell, and fibroblast proliferation and migration in vitro. Like bFGF, they also enhance angiogenesis and neovascularization in vivo (reviewed in [6,74]). Thus, increased NEP compromises re-epithelialization and wound healing, potentially by degrading growth factors such as bFGF2 [26] and SP, which may facilitate development of diabetic ulcers [62]. Despite an improvement of extracutaneous wound healing after concomitantly applied SP and NEP inhibitors [7], these agents may exacerbate neuroinflammation and contribute to hypertrophic scar 
formation [80]. However, in pathologic cutaneous scar tissue, an increased expression of ACE in comparison to normal or wounded skin, particularly by myofibroblasts, was detected. Potentially, by generating abundant Ang II, ACE may have profibrotic and, thus, adverse effects on cutaneous wound healing similar to remodeling in the heart after myocardial infarct $[54,92]$.

\subsubsection{Development of Neoplasms: Shutting Off Growth-Promoting Signals is the Key}

Allergens or irritants such as cigarette smoke impair NEP expression and activity in the lung, which may increase respiratory distress and neurogenic inflammation. Moreover, reduced NEP activity in certain forms of prostate or lung carcinoma prevents hydrolysis of mitogens such as bombesins, ET-1, or SP, which may promote peptide-driven tumor growths $[84,95]$. Likewise, reduced NEP activity hampers generation of the growth inhibitory fragment $\mathrm{SP}_{1-7}$ from NEP cleavage of SP [22]. One of the discussed mechanisms is an indirect phosphorylation and activation of the insulin growth factor 1 receptor (IGF-1R) that, further downstream, activates protein kinase B (Akt) anti-apoptotic cell survival pathways [95]. In line with this hypothesis, $\mathrm{T}$ and $\mathrm{B}$ cells become CD10-positive when undergoing apoptosis [16,53]. Hence, NEP expression represents a safety device that protects cells from mediators released from apoptotic cells and assures apoptotic cell-death by preventing access of cell survival-assuring mitogens. Interestingly, an apparent positive correlation of higher NEP levels with the malignancy of melanoma have been observed $[4,102]$. This increased NEP expression was accompanied by downregulated anti-apoptotic and upregulated pro-apoptotic proteins (Bcl-2, and Bax, respectively) [4]. Thus, NEP serves as a marker for apoptosis and progression of melanoma. However, the divergent expression pattern of NEP in metastatic melanoma, in contrast to other cancers, suggests that NEP may have diverse and tumor-specific modulating properties that require detailed future analysis. Noteworthy in this context, not all effects of vasopeptidases can be attributed to changes in extracellular mediator levels. Very recently, an ACE inhibitor-induced dimerization, phosphorylation, and signaling of ACE has been demonstrated in EC that enhanced endothelial ACE expression [43]. Likewise, as demonstrated for ACE, NEP, and tachykinin or BK receptors, the cellular co-expression [61] or a sterically close receptor--peptidase association is important for receptor function and resensitization $[18,21,48]$.
Therefore, direct vasopeptidase outside-in signaling or modulation of G protein-coupled receptor (GPCR) signal transduction independent of ligand cleavage may account for some effects of NEP or ACE inhibitors that require future analysis.

\subsubsection{NEP and ACE: Are There Functional Roles in Psoriasis, Alopecia Areata, and Acne?}

Innervation of the pilosebaceous unit plays a pivotal role for sebocyte function and hair growth. Stress-induced SP promotes both proliferation and differentiation of sebaceous glands, resulting in an increased size and lipogenesis. Surprisingly, in skin of acne patients in contrast to normal skin, the subcellular expression of SPinduced NEP is increased in germinal sebocytes [97]. This may argue against a stress-induced inflammation, although the exact role of increased NEP awaits future investigation. Likewise, in acute and late stage chronic alopecia areata, NEP is strongly expressed in follicular structures of the affected area, whereas the perivascular expression of ACE in alopecia areata lesions is diminished [98]. This may prevent the local generation of keratinocyte/fibroblast proliferation-inducing Ang II [90]. As SP is capable of inducing significant anagen hair growth, limited bioavailability of SP, Ang II, and growth factors in alopecia areata may attenuate hair growth and increase hair follicle regression and apoptosis $[64,65]$. Uncontrolled cellular access to sensory neuropeptides and growth factors may also contribute to the pathogenesis of psoriasis. A reduced NEP expression in acute psoriatic lesions, but not in healthy skin, may locally increase SP levels that contribute to keratinocyte hyperproliferation, inflammation, and psoriatic pruritus $[12,57,75]$. In conjunction with a reportedly enhanced neuronal density and $\mathrm{NK}_{1}$ expression, this may explain, in part, the susceptibility of psoriasis to exogenous stress and, thus, $\mathrm{NK}_{1}$ antagonists might be beneficial in psoriasis therapy [40]. Likewise, ACE has been associated with this disease [63], although the exact role of the enzyme is somewhat obscure. Some studies proposed elevated serum ACE levels in psoriasis as a diagnostic marker and suggested that increased amounts of the pro-inflammatory Ang II may contribute to the pathogenesis of this disease [32,70]. Several other reports, however, have associated pharmacologic ACE inhibition with the induction or exacerbation of psoriasis $[14,33,107]$. Thus, one adverse side-effect of vasopeptidase inhibitors may be the worsening of psoriasis due to prolonged availability of SP or BK. 


\section{Summary for the Clinician}

As outlined in this chapter, endopeptidases have multiple substrates and different modes of action in the skin and elsewhere. Particularly, NEP is an excellent example that endopeptidases in addition to their metabolizing/degrading function mediate biotransformation of inert precursor peptides to active mediators, and act as convertases by converting one bioactive receptor ligand into a second peptide that activates another receptor. Finally, competitive cleavage of a given substrate generates a peptide with opposing physiological effects to that produced by a closely related enzyme (i.e., NEP: Ang I $\rightarrow$ Ang $_{1-7}$, hypotensive vs. ACE: Ang I $\rightarrow$ Ang II $=$ Ang $_{1-8}$, hypertensive). Evidently, a multiplicity of functions arises from these activities, and thus endopeptidases constitute important milestones in cardiovascular regulation, in neurogenic inflammation and immune recognition, or in tumorigenesis. Although it is tempting to drug-target neprilysin and others to achieve expressional or enzymatic regulation, one may likely replace one evil with another. This dilemma is best exemplified by attempts to simultaneously inhibit multiple vasopeptidases (ACE, NEP, and ECE) with one inhibitor. Although this is a promising strategy for the treatment of cardiovascular disorders, recent large-scale phase IV clinical studies have questioned this benefit [9]. Evidently, the ACE/NEP inhibitor-dependently increased kinin, SP, and endothelin levels elevated the risk of potentially life-threatening angioedema, with an even higher incidence particularly in African-Americans [66] Vasopeptidase inhibition may also worsen cutaneous disorders with a neurogenic component [91], promote Ag sensitization, or trigger elicitation of allergic inflammation in already sensitized individuals. As explained above, NEP may also have (neuro-) protective roles in cancer and Alzheimer's disease [35]. Thus, future attempts of inhibiting peptidases with $\mathrm{A} \beta$-catabolizing properties essentially require the design of drugs incapable of crossing the bloodbrain-barrier, and critical validation of efficacy and safety of this promising therapeutic principle is mandatory. Vice versa, since downregulated NEP expression or activity frequently accompanies acute or chronic inflammation and the malignancy of tumors, an artificial substitution seems to be desirable. Thus, a tissue-specific use of recombinant enzymes [94] or a local enhancement of NEP expression and activity may provide a novel mechanism-based therapeutic approach towards management of (neurogenic) inflammatory skin disorders. Unfortunately, despite a revived interest in NEP regulation due to the impact of NEP on the CNS A $\beta$ level, only few data are available demonstrating an upregulation of NEP, that is, by glucocorticoids, thrombin, or cAMP $[28,29,35]$. Obviously, the future challenge remains to develop tools to control peptidase expression and activity in a highly selective cell and tissue-specific manner.

\section{References}

1. Aberdam E, Auberger P, Ortonne JP, Ballotti R (2000) Neprilysin, a novel target for ultraviolet $B$ regulation of melanogenesis via melanocortins. J Invest Dermatol 115:381-387

2. Aliberti J, Viola JP, Vieira-de-Abreu A, Bozza PT, Sher A, Scharfstein J (2003) Cutting edge: bradykinin induces IL12 production by dendritic cells: a danger signal that drives Th1 polarization. J Immunol 170:5349-5353

3. Battistini B, Daull P, Jeng AY (2005) CGS 35601, a triple inhibitor of angiotensin converting enzyme, neutral endopeptidase and endothelin converting enzyme. Cardiovasc Drug Rev 23:317-330

4. Bilalovic N, Sandstad B, Golouh R, Nesland JM, Selak I, Torlakovic EE (2004) CD10 protein expression in tumor and stromal cells of malignant melanoma is associated with tumor progression. Mod Pathol 17:1251-1258

5. Bock O, Kreiselmeyer I, Mrowietz U (2001) Expression of dipeptidyl-peptidase IV (CD26) on CD8 + T cells is significantly decreased in patients with psoriasis vulgaris and atopic dermatitis. Exp Dermatol 10:414-419

6. Brain SD (1997) Sensory neuropeptides: their role in inflammation and wound healing. Immunopharmacology 37:133-152

7. Burssens P, Steyaert A, Forsyth R, van Ovost EJ, De PY, Verdonk R (2005) Exogenously administered substance P and neutral endopeptidase inhibitors stimulate fibroblast proliferation, angiogenesis and collagen organization during Achilles tendon healing. Foot Ankle Int 26:832-839

8. Busso N, Wagtmann N, Herling C, Chobaz-Peclat V, Bischof-Delaloye A, So A, et al. (2005) Circulating CD26 is negatively associated with inflammation in human and experimental arthritis. Am J Pathol 166:433-442

9. Campbell DJ (2003) Vasopeptidase inhibition: a doubleedged sword? Hypertension 41:383-389

10. Castro MG, Morrison E (1997) Post-translational processing of proopiomelanocortin in the pituitary and in the brain. Crit Rev Neurobiol 11:35-57

11. Catania A, Gatti S, Colombo G, Lipton JM (2004) Targeting melanocortin receptors as a novel strategy to control inflammation. Pharmacol Rev 56:1-29

12. Chan J, Smoller BR, Raychauduri SP, Jiang WY, Farber EM (1997) Intraepidermal nerve fiber expression of calcitonin gene-related peptide, vasoactive intestinal peptide and substance P in psoriasis. Arch Dermatol Res 289:611-616

13. Chen T, Ajami K, McCaughan GW, Gorrell MD, Abbott CA (2003) Dipeptidyl peptidase IV gene family. The DPIV family. Adv Exp Med Biol 524:79-86

14. Cohen AD, Bonneh DY, Reuveni H, Vardy DA, Naggan L, Halevy S (2005) Drug exposure and psoriasis vulgaris: case-control and case-crossover studies. Acta Derm Venereol 85:299-303

15. Costerousse O, Allegrini J, Lopez M, Alhenc-Gelas F (1993) Angiotensin I-converting enzyme in human circulating mononuclear cells: genetic polymorphism of expression in T-lymphocytes. Biochem J 290(Pt 1):33-40

16. Cutrona G, Ferrarini M (2001) Expression of CD10 by human $\mathrm{T}$ cells that undergo apoptosis both in vitro and in vivo. Blood 97:2528

17. Danilov SM, Sadovnikova E, Scharenborg N, Balyasnikova IV, Svinareva DA, Semikina EL, et al. (2003) Angiotensinconverting enzyme (CD143) is abundantly expressed by 
dendritic cells and discriminates human monocyte-derived dendritic cells from acute myeloid leukemia-derived dendritic cells. Exp Hematol 31:1301-1309

18. Deddish PA, Marcic B, Tan F, Jackman HL, Chen ZZ, Erdos EG (2002) Neprilysin inhibitors potentiate effects of bradykinin on B2 receptor. Hypertension 39:619-623

19. Doyle HA, Mamula MJ (2001) Post-translational protein modifications in antigen recognition and autoimmunity. Trends Immunol 22:443-449

20. Dubovy P (1987) Histochemical evidence for the presence of dipeptidylpeptidase IV in the Schwann cells of skin unmyelinated axons. Experientia 43:883-884

21. Erdos EG, Marcic BM (2001) Kinins, receptors, kininases and inhibitors - where did they lead us? Biol Chem 382:43-47

22. Erin N, Zhao W, Bylander J, Chase G, Clawson G (2006) Capsaicin-induced inactivation of sensory neurons promotes a more aggressive gene expression phenotype in breast cancer cells. Breast Cancer Res Treat 99:351-364

23. Fastrich M, Fabritz L, Luger TA, Scholzen TE (2006) Neprilysin/angiotensin-converting enzyme double-deficient mice: a mouse model to study inflammatory skin disease. J Invest Dermatol 126:1675

24. Gliddon DR, Howard CJ (2002) CD26 is expressed on a restricted subpopulation of dendritic cells in vivo. Eur J Immunol 32:1472-1481

25. Gonzalez-Rey E, Chorny A, Delgado M (2007) Regulation of immune tolerance by anti-inflammatory neuropeptides. Nat Rev Immunol 7:52-63

26. Goodman OB, Jr., Febbraio M, Simantov R, Zheng R, Shen R, Silverstein RL, et al. (2006) Neprilysin inhibits angiogenesis via proteolysis of fibroblast growth factor-2. J Biol Chem 281:33597-33605

27. Gorrell MD (2005) Dipeptidyl peptidase IV and related enzymes in cell biology and liver disorders. Clin Sci (Lond) 108:277-292

28. Graf K, Kunkel K, Zhang M, Grafe M, Schultz K, Schudt C, et al. (1995) Activation of adenylate cyclase and phosphodiesterase inhibition enhance neutral endopeptidase activity in human endothelial cells. Peptides 16: 1273-1278

29. Graf K, Koehne P, Grafe M, Zhang M, Auch-Schwelk W, Fleck E (1995) Regulation and differential expression of neutral endopeptidase 24.11 in human endothelial cells. Hypertension 26:230-235

30. Guy JL, Lambert DW, Warner FJ, Hooper NM, Turner AJ (2005) Membrane-associated zinc peptidase families: comparing ACE and ACE2. Biochim Biophys Acta 1751:2-8

31. Hamming I, Timens W, Bulthuis ML, Lely AT, Navis GJ, van GH (2004) Tissue distribution of ACE2 protein, the functional receptor for SARS coronavirus. A first step in understanding SARS pathogenesis. J Pathol 203:631-637

32. Huskic J, Alendar F, Matavulj A, Ostoic L (2004) Serum angiotensin converting enzyme in patients with psoriasis. Med Arh 58:202-205

33. Ikai K (1995) Exacerbation and induction of psoriasis by angiotensin-converting enzyme inhibitors. J Am Acad Dermatol 32:819

34. Ishimaru F, Potter NS, Shipp MA (1996) Phorbol estermediated regulation of CD10/neutral endopeptidase transcripts in acute lymphoblastic leukemias. Exp Hematol $24: 43-48$
35. Iwata N, Higuchi M, Saido TC (2005) Metabolism of amyloid-beta peptide and Alzheimer's disease. Pharmacol Ther 108:129-148

36. Jaspard E, Wei L, Alhenc-Gelas F (1993) Differences in the properties and enzymatic specificities of the two active sites of angiotensin I-converting enzyme (kininase II). Studies with bradykinin and other natural peptides. J Biol Chem 268:9496-9503

37. Jongun L (2004) Reciprocal regulation of angiotensin converting enzyme and neutral endopeptidase in rats with experimental hypertension. Physiol Res 53:365-368

38. Joshi DD, Dang A, Yadav P, Qian J, Bandari PS, Chen K, et al. (2001) Negative feedback on the effects of stem cell factor on hematopoiesis is partly mediated through neutral endopeptidase activity on substance P: a combined functional and proteomic study. Blood 98:2697-2706

39. Khatib AM, Siegfried G, Chretien M, Metrakos P, Seidah NG (2002) Proprotein convertases in tumor progression and malignancy: novel targets in cancer therapy. Am J Pathol 160:1921-1935

40. Kikwai L, Babu RJ, Kanikkannan N, Singh M (2004) Preformulation stability of Spantide II, a promising topical anti-inflammatory agent for the treatment of psoriasis and contact dermatitis. J Pharm Pharmacol 56:19-25

41. Kim EJ, Hess S, Richardson SK, Newton S, Showe LC, Benoit BM, et al. (2005) Immunopathogenesis and therapy of cutaneous T cell lymphoma. J Clin Invest 115:798-812

42. Koenig S, Luger TA, Scholzen TE (2006) Monitoring neuropeptide-specific proteases: processing of the proopiomelanocortin peptides adrenocorticotropin and $\alpha$-melanocyte-stimulating hormone in the skin. Exp Dermatol 15:751-761

43. Kohlstedt K, Brandes RP, Muller-Esterl W, Busse R, Fleming I (2004) Angiotensin-converting enzyme is involved in outside-in signaling in endothelial cells. Circ Res 94:60-67

44. Krege JH, John SW, Langenbach LL, Hodgin JB, Hagaman JR, Bachman ES, et al. (1995) Male-female differences in fertility and blood pressure in ACE-deficient mice. Nature 375:146-148

45. Lambrecht $\mathrm{BN}$ (2001) Immunologists getting nervous: neuropeptides, dendritic cells and $\mathrm{T}$ cell activation. Respir Res 2:133-138

46. Lapteva N, Nieda M, Ando Y, Ide K, Hatta-Ohashi Y, Dymshits G, et al. (2001) Expression of renin-angiotensin system genes in immature and mature dendritic cells identified using human cDNA microarray. Biochem Biophys Res Commun 285:1059-1065

47. Lapteva N, Ide K, Nieda M, Ando Y, Hatta-Ohashi Y, Minami M, et al. (2002) Activation and suppression of renin-angiotensin system in human dendritic cells. Biochem Biophys Res Commun 296:194-200

48. Marcic B, Deddish PA, Skidgel RA, Erdos EG, Minshall R, Tan F (2000) Replacement of the transmembrane anchor in angiotensin I-converting enzyme (ACE) with a glycosylphosphatidylinositol tail affects activation of the B2 bradykinin receptor by ACE inhibitors. J Biol Chem 275:16110-16118

49. Mazurkiewicz JE, Corliss D, Slominski A (1999) Differential temporal and spatial expression of POMC mRNA and of the production of POMC peptides during the murine hair cycle. Ann N Y Acad Sci 885:427-429 
50. Mbikay M, Seidah NG, Chretien M (2001) Neuroendocrine secretory protein $7 \mathrm{~B} 2$ : structure, expression and functions. Biochem J 357:329-342

51. Miyoshi S, Nakazawa H, Kawata K, Tomochika K, Tobe K, Shinoda S (1998) Characterization of the hemorrhagic reaction caused by Vibrio vulnificus metalloprotease, a member of the thermolysin family. Infect Immun 66:4851-4855

52. Miyoshi S, Watanabe H, Kawase T, Yamada H, Shinoda S (2004) Generation of active fragments from human zymogens in the bradykinin-generating cascade by extracellular proteases from Vibrio vulnificus and $V$. parahaemolyticus. Toxicon 44:887-893

53. Morabito F, Mangiola M, Rapezzi D, Zupo S, Oliva BM, Ferraris AM, et al. (2003) Expression of CD10 by B-chronic lymphocytic leukemia cells undergoing apoptosis in vivo and in vitro. Haematologica 88:864-873

54. Morihara K, Takai S, Takenaka H, Sakaguchi M, Okamoto Y, Morihara T, et al. (2006) Cutaneous tissue angiotensinconverting enzyme may participate in pathologic scar formation in human skin. J Am Acad Dermatol 54:251-257

55. Morrison ME, Vijayasaradhi S, Engelstein D, Albino AP, Houghton AN (1993) A marker for neoplastic progression of human melanocytes is a cell surface ectopeptidase. J Exp Med 177:1135-1143

56. Nahmod KA, Vermeulen ME, Raiden S, Salamone G, Gamberale R, Fernandez-Calotti P, et al (2003) Control of dendritic cell differentiation by angiotensin II. FASEB J 17:491-493

57. Nakamura M, Toyoda M, Morohashi M (2003) Pruritogenic mediators in psoriasis vulgaris: comparative evaluation of itchassociated cutaneous factors. Br J Dermatol 149:718-730

58. Narducci MG, Scala E, Bresin A, Caprini E, Picchio MC, Remotti D, et al. (2006) Skin homing of Sezary cells involves SDF-1-CXCR4 signaling and down-regulation of CD26/dipeptidylpeptidase IV. Blood 107:1108-1115

59. Nemoto E, Sugawara S, Takada H, Shoji S, Horiuch H (1999) Increase of CD26/dipeptidyl peptidase IV expression on human gingival fibroblasts upon stimulation with cytokines and bacterial components. Infect Immun 67:6225-6233

60. Novelli M, Savoia P, Fierro MT, Verrone A, Quaglino P, Bernengo MG (1996) Keratinocytes express dipeptidylpeptidase IV (CD26) in benign and malignant skin diseases. Br J Dermatol 134:1052-1056

61. Okamoto A, Lovett M, Payan DG, Bunnett NW (1994) Interactions between neutral endopeptidase (EC 3.4.24.11) and the substance $\mathrm{P}$ (NK1) receptor expressed in mammalian cells. Biochem J 299:683-693

62. Olerud JE, Usui ML, Seckin D, Chiu DS, Haycox CL, Song IS, et al. (1999) Neutral endopeptidase expression and distribution in human skin and wounds. J Invest Dermatol 112:873-881

63. Ozkur M, Erbagci Z, Nacak M, Tuncel AA, Alasehirli B, Aynacioglu AS (2004) Association of insertion/deletion polymorphism of the angiotensin-converting enzyme gene with psoriasis. Br J Dermatol 151:792-795

64. Paus R, Heinzelmann T, Schultz KD, Furkert J, Fechner K, Czarnetzki BM (1994) Hair growth induction by substance P. Lab Invest 71:134-140

65. Peters EMJ, Ericson ME, Hosoi J, Seiffert K, Hordinsky MK, Ansel JC, et al. (2006) Neuropeptide control mechanisms in cutaneous biology: physiological and clinical significance. J Invest Dermatol 126:1937-1947
66. Pickering TG (2002) The rise and fall of omapatrilat. J Clin Hypertens 4:371-373

67. Roesch A, Wittschier S, Becker B, Landthaler M, Vogt T (2006) Loss of dipeptidyl peptidase IV immunostaining discriminates malignant melanomas from deep penetrating nevi. Mod Pathol 19:1378-1385

68. Roosterman D, Goerge T, Schneider SW, Bunnett NW, Steinhoff M (2006) Neuronal control of skin function: the skin as a neuroimmunoendocrine organ. Physiol Rev 86:1309-1379

69. Roques BP, Noble F, Dauge V, Fournie-Zaluski MC, Beaumont A (1993) Neutral endopeptidase 24.11: structure, inhibition, and experimental and clinical pharmacology. Pharmacol Rev 45:87-146

70. Ryder KW, Epinette WW, Jay SJ, Ransburg RC, Glick MR (1985) Serum angiotensin converting enzyme activity in patients with psoriasis. Clin Chim Acta 153:143-146

71. Scamuffa N, Calvo F, Chretien M, Seidah NG, Khatib AM (2006) Proprotein convertases: lessons from knockouts. FASEB J 20:1954-1963

72. Scheel-Toellner D, Richter E, Toellner KM, Reiling N, Wacker HH, Flad HD, et al. (1995) CD26 expression in leprosy and other granulomatous diseases correlates with the production of interferon-gamma. Lab Invest 73:685-690

73. Schiller M, Brzoska T, Bohm M, Metze D, Scholzen TE, Rougier A, et al. (2004) Solar-simulated ultraviolet radiation-induced upregulation of the melanocortin-1 receptor, proopiomelanocortin, and \{alpha\}-melanocytestimulating hormone in human epidermis in vivo. J Invest Dermatol 122:468-476

74. Scholzen T, Armstrong CA, Bunnett NW, Luger TA, Olerud JE, Ansel JC (1998) Neuropeptides in the skin: interactions between the neuroendocrine and the skin immune systems. Exp Dermatol 7:81-96

75. Scholzen TE, Luger TA (2004) Neutral endopeptidase and angiotensin-converting enzyme - key enzymes terminating the action of neuroendocrine mediators. Exp Dermatol $13: 22-26$

76. ScholzenTE, Kalden D-H, BrzoskaT, Fastrich M, SchwarzT, Schiller M, et al. (2000) Expression of proopiomelanocortin peptides in human dermal microvascular endothelial cells: evidence for a regulation by ultraviolet light and interleukin-1. J Invest Dermatol 115:1021-1028

77. Scholzen TE, Steinhoff M, Bonaccorsi P, Klein R, Amadesi S, Geppetti P, et al. (2001) Neutral endopeptidase terminates substance P-induced inflammation in allergic contact dermatitis. J Immunol 166:1285-1291

78. Scholzen TE, Stander S, Riemann H, Brzoska T, Luger TA (2003) Modulation of cutaneous inflammation by angiotensin-converting enzyme. J Immunol 170:3866-3873

79. Scholzen TE, Steinhoff M, Sindrilaru A, Schwarz A, Bunnett NW, Luger TA, et al. (2004) Cutaneous allergic contact dermatitis responses are diminished in mice deficient in neurokinin 1 receptors and augmented by neurokinin 2 receptor blockage. FASEB J 18:1007-1009

80. Scott JR, Muangman PR, Tamura RN, Zhu KQ, Liang Z, Anthony J, et al. (2005) Substance P levels and neutral endopeptidase activity in acute burn wounds and hypertrophic scar. Plast Reconstr Surg 115:1095-1102

81. Seidah NG, Benjannet S, Hamelin J, Marmabachi AM, Basak A, Marcinkiewicz J, et al. (1999) The subtilisin/ kexin family of precursor convertases: emphasis on PC1, 
PC2/7B2, POMC and the novel enzyme SKI-1. Ann N Y Acad Sci 885:57-74

82. Seitzer U, Scheel-Toellner D, Hahn M, Heinemann G, Mattern T, Flad HD, et al. (1997) Comparative study of CD26 as a Th1-like and CD30 as a potential Th2-like operational marker in leprosy. Adv Exp Med Biol 421:217-221

83. Sherman LA, Burke TA, Biggs JA (1992) Extracellular processing of peptide antigens that bind class I major histocompatibility molecules. J Exp Med 175:1221-1226

84. Shipp MA, Look AT (1993) Hematopoietic differentiation antigens that are membrane-associated enzymes: cutting is the key! Blood 82:1052-1070

85. Simeoni L, Rufini A, Moretti T, Forte P, Aiuti A, Fantoni A (2002) Human CD26 expression in transgenic mice affects murine T-cell populations and modifies their subset distribution. Hum Immunol 63:719-730

86. Skidgel RA, Erdos EG (2004) Angiotensin converting enzyme (ACE) and neprilysin hydrolyze neuropeptides: a brief history, the beginning and follow-ups to early studies. Peptides 25:521-525

87. Slominski A, Wortsman J, Luger TA, Paus R, Solomon SG (2000) Corticotropin releasing hormone and proopiomelanocortin involvement in the cutaneous response to stress. Physiol Rev 80:979-1020

88. Sokolowska-Wojdylo M, Wenzel J, Gaffal E, Steitz J, Roszkiewicz J, Bieber T, et al. (2005) Absence of CD26 expression on skin-homing CLA+ CD4+ T lymphocytes in peripheral blood is a highly sensitive marker for early diagnosis and therapeutic monitoring of patients with Sezary syndrome. Clin Exp Dermatol 30:702-706

89. Steckelings UM, Czarnetzki BM (1995) The renin-angiotensin-system in the skin. Evidence for its presence and possible functional implications. Exp Dermatol 4:329-334

90. Steckelings UM, Artuc M, Paul M, Stoll M, Henz BM (1996) Angiotensin II stimulates proliferation of primary human keratinocytes via a non-AT1, non-AT2 angiotensin receptor. Biochem Biophys Res Commun 229:329-333

91. Steckelings UM, Artuc M, Wollschlager T, Wiehstutz S, Henz BM (2001) Angiotensin-converting enzyme inhibitors as inducers of adverse cutaneous reactions. Acta Derm Venereol 81:321-325

92. Steckelings UM, Wollschlager T, Peters J, Henz BM, Hermes B, Artuc M (2004) Human skin: source of and target organ for angiotensin II. Exp Dermatol 13:148-154

93. Steinman L (2004) Elaborate interactions between the immune and nervous systems. Nat Immunol 5:575-581

94. Sturiale S, Barbara G, Qui B, Figini M, Geppetti P, Gerard $\mathrm{N}$, et al. (1999) Neutral endopeptidase (EC 3.4.24.11) terminates colitis by degrading SP. Proc Natl Acad Sci U S A 96:11653-11658
95. Sumitomo M, Shen R, Nanus DM (2005) Involvement of neutral endopeptidase in neoplastic progression. Biochim Biophys Acta 1751:52-59

96. Thomas JE, Rylett CM, Carhan A, Bland ND, Bingham RJ, Shirras AD, et al. (2005) Drosophila melanogaster NEP2 is a new soluble member of the neprilysin family of endopeptidases with implications for reproduction and renal function. Biochem J 386:357-366

97. Toyoda M, Morohashi M (2003) New aspects in acne inflammation. Dermatology 206:17-23

98. Toyoda M, Makino T, Kagoura M, Morohashi M (2001) Expression of neuropeptide-degrading enzymes in alopecia areata: an immunohistochemical study. Br J Dermatol 144:46-54

99. Turner AJ, Hooper NM (2002) The angiotensin-converting enzyme gene family: genomics and pharmacology. Trends Pharmacol Sci 23:177-183

100. Turner AJ, Isaac RE, Coates D (2001) The neprilysin (NEP) family of zinc metalloendopeptidases: genomics and function. Bioessays 23:261-269

101. Van den Oord JJ (1998) Expression of CD26/dipeptidylpeptidase IV in benign and malignant pigment-cell lesions of the skin. Br J Dermatol 138:615-621

102. VelazquezEF,YancovitzM,PavlickA,BermanR, ShapiroR, Bogunovic D, et al. (2007) Clinical relevance of neutral endopeptidase (NEP/CD10) in melanoma. J Transl Med $5: 2$

103. Wang XM, Yu DM, McCaughan GW, Gorrell MD (2006) Extra-enzymatic roles of DPIV and FAP in cell adhesion and migration on collagen and fibronectin. Adv Exp Med Biol 575:213-222

104. Watts C, Matthews SP, Mazzeo D, Manoury B, Moss CX (2005) Asparaginyl endopeptidase: case history of a class II MHC compartment protease. Immunol Rev 207:218-228

105. Wei L, Clauser E, henc-Gelas F, Corvol P (1992) The two homologous domains of human angiotensin I-converting enzyme interact differently with competitive inhibitors. J Biol Chem 267:13398-13405

106. Wesley UV, McGroarty M, Homoyouni A (2005) Dipeptidyl peptidase inhibits malignant phenotype of prostate cancer cells by blocking basic fibroblast growth factor signaling pathway. Cancer Res 65:1325-1334

107. Wolf R, Tamir A, Brenner S (1990) Psoriasis related to angiotensin-converting enzyme inhibitors. Dermatologica 181:51-53

108. Yellen-Shaw AJ, Laughlin CE, Metrione RM, Eisenlohr LC (1997) Murine transporter associated with antigen presentation (TAP) preferences influence class I-restricted T cell responses. J Exp Med 186:1655-1662 